ISSN 0103-5150

Fisioter. Mov., Curitiba, v. 24, n. 1, p. 167-172, jan./mar. 2011 Licenciado sob uma Licença Creative Commons

\title{
Comparação dos exercícios em cadeia cinética aberta e cadeia cinética fechada na reabilitação da disfunção femoropatelar
}

\author{
Comparison of exercise open kinetic chain and closed kinetic chain \\ in the rehabilitation of patellofemoral dysfunction
}

\section{Thatiana Lacerda Nobre}

Fisioterapeuta, Especialista em Bases Fisiológicas e Metodológicas do Treinamento Desportivo pela Universidade Federal de São Paulo (UNIFESP) e em 0 Aparelho Locomotor no Esporte pela Universidade Federal de São Paulo (UNIFESP), São Paulo, SP - Brasil, e-mail: thatianalacerda@yahoo.com.br

\section{Resumo}

Introdução: A disfunção femoropatelar (DFP) é uma patologia caracterizada por dor na região patelofemoral resultante de alterações físicas e biomecânicas dessa articulação. Seu índice de incidência é alto, representando uma queixa comum em cerca de $20 \%$ da população, e sua etiologia ainda permanece desconhecida. Objetivo: Esta revisão de literatura tem como objetivo comparar a eficácia dos exercícios em cadeia cinética aberta com os em cadeia cinética fechada, para a recuperação funcional dos portadores da disfunção femoropatelar. Metodologia: Foi realizada uma revisão sistemática nas bases de dados LILACS, MEDLINE, SciELO e PubMed como termo de procura das palavras disfunção femoropatelar, cadeia cinética aberta e cadeia cinética fechada. Discussão: O desequilíbrio de forças dos estabilizadores dinâmicos da patela, do vasto medial oblíquo (VMO) e do vasto lateral (VL) ainda é considerado o fator primordial para o surgimento dos sintomas, já que essa alteração causa o aumento das forças de reação e compressão femoropatelar. Com a finalidade de recuperar o equilíbrio da forças dos músculos que atuam como estabilizadores do joelho e como forma de restituir estabilidade à articulação, os exercícios em cadeia cinética aberta (CCA) e em cadeia cinética fechada (CCF) têm sido empregados em programas de reabilitação dos distúrbios femoropatelares. Conclusão: Os benefícios para a aplicação desses protocolos não são bem documentados, faltando evidências científicas para comprovar a real eficácia desses exercícios na melhora do desempenho do músculo quadríceps femoral ou auxiliar no equilíbrio muscular dos estabilizadores dinâmicos da patela.

Palavras-chave: Reabilitação patelofemoral. Cadeia cinética aberta. Cadeia cinética fechada. Disfunção femoropatelar. Força patelofemoral. 


\section{Abstract}

Introduction: The patellofemoral syndrome (DFP) is a disease characterized by pain in the patellofemoral and physical changes resulting from this joint biomechanics. The rate of incidence is high, representing a common complaint in about $20 \%$ of the population. Its etiology remains unknown. Objective: This literature review aims to compare the effectiveness of open kinetic chain exercises with closed kinetic chain into the functional recovery of patients with the patellofemoral syndrome. Methods: We conducted a systematic review in the database LILACS, MEDLINE, PUbMed and SciELO as search term words patellofemoral syndrome, open kinetic chain and closed kinetic chain. Discussion: The imbalance of forces of the dynamic stabilizers of the patella, vastus medialis oblique (VMO) and vastus lateralis (VL), is still considered the primary factor for the onset of symptoms. Since this change causes an increase in reaction force and patellofemoral compression. In order to recover the balance of forces of the muscles acting as stabilizers of the knee and as a means of restoring stability to the joint, exercises in open kinetic chain (OKC) and closed kinetic chain (CKC) has been used in rehabilitation programs patellofemoral disorders. Conclusion: The benefits for implementing these protocols are not well documented, lacking scientific evidence to prove the real effectiveness of these exercises in improving the performance of the quadriceps muscle or assist in muscle balance of the dynamic stabilizers of the patella.

Keywords: Rehabilitation syndrome. Open kinectic chain. Closed kinectic chain. Patellofemoral dysfunction. Patellofemoral force.

\section{Introdução}

A disfunção femoropatelar é uma das desordens musculoesqueléticas mais frequentes no joelho (1$3)$. Seus sintomas consistem em dor difusa na face anterior do joelho, normalmente ao longo do aspecto medial da patela, podendo, também, serem diagnosticadas as dores retropatelar e na face lateral (4). Esses sintomas são decorrentes de alterações estruturais ou biomecânicas da articulação, a qual se torna exacerbada por atividades como descer e subir escadas, sentar por um período prolongado, agachar ou ajoelhar $(2,5)$, resultando no aumento das forças compressivas na articulação femoropatelar $(4,6)$. Outros sinais também estão presentes como a crepitação patelar, o edema e o bloqueio articular (6).

Essa patologia acomete atletas e não atletas e representa um problema comum no joelho de adolescentes e adultos jovens fisicamente ativos (5-7). Sua etiologia ainda não está claramente estabelecida $(2,3,6)$, porém, pode ser relacionada a alterações biomecânicas, destacando-se, dentre esses fatores, o desequilíbrio estático e dinâmico (1).

Nas alterações estáticas, alguns autores apontam anormalidades como o mau alinhamento patelar, o aumento do ângulo $\mathrm{Q}$, a patela alta ou baixa, a pronação subtalar excessiva, a rotação lateral da tíbia, a anteversão femoral, os joelhos valgos ou varos e o encurtamento do retináculo lateral, dos músculos isquiotibiais e do tracto iliotibial $(1,6)$. Dessa forma, um comportamento inadequado da patela pode causar dor na região anterior do joelho (5).

A superfície patelar do fêmur é a porção articular anterior que se articula com a patela e divide-se em duas facetas: lateral e medial. A faceta lateral é, em geral, maior e projetada mais anteriormente, na maioria das pessoas, que a faceta medial (8). Nota-se em sua anatomia uma concavidade em dois planos, promovendo um contato íntimo com o côndilo femoral lateral durante a maior parte da amplitude do movimento articular (9). Essa faceta ajuda a manter a patela centralizada na superfície patelar do fêmur durante a função normal do joelho. Quando há uma instabilidade lateral da patela, nota-se uma variação da superfície patelar do fêmur (8). Já a faceta medial é pouco convexa, e somente uma pequena porção de sua superfície entra em contato com o côndilo femoral medial (9).

A cartilagem articular que cobre a superfície patelar do fêmur é mais fina que a da patela e, também, mais fina sobre a faceta medial que a lateral (8). A cartilagem patelar é mais permeável e elástica se comparada com as outras cartilagens do corpo. Dessa forma, com a carga, sua área de contato aumenta, diminuindo a pressão (10).

A patela é o ponto central onde convergem os elementos retinaculares: ligamentos, músculos, tendões e cápsula sinovial (8). Por causa da incongruência 
e da capacidade de se movimentar em relação ao fêmur, o ponto de contato na patela muda com a flexão ou extensão do joelho (10). Quando em extensão completa e com o quadríceps contraído, a patela articula-se com o corpo adiposo suprapatelar e, quando em flexão completa, com a parte dos côndilos femorais medial e lateral que se articula com os planaltos tibiais em extensão completa (8).

0 tracionamento dinâmico da patela é afetado por uma série de forças que tendem a deslocá-la tanto medial como lateralmente. Essas forças entram em ação quando o sistema nervoso ativa o controle dos músculos atuantes sobre a patela (11).

A principal estrutura responsável por ativar as forças exercidas na patela é o músculo quadríceps da coxa, que tem como função controlar a posição da patela em relação à tróclea, por meio das fibras oblíquas de suas porções medial e lateral, sendo os músculos: vasto medial (VM) e vasto lateral (VL) (11).

0 músculo VM é dividido em duas porções, uma proximal, denominada de vasto medial longo (VML), e outra distal, o vasto medial oblíquo (VMO). Essas porções apresentam diferenças anatômicas, funcionais, histoquímicas e também no padrão de inervação (1). 0 músculo vasto medial lateral (VML) se insere num ângulo de $15^{\circ}$ em relação ao eixo longitudinal do fêmur, exercendo pouca ou nenhuma tração para o adequado posicionamento da patela, e o músculo vasto medial oblíquo (VMO), que se origina principalmente do tendão do músculo adutor magno e se insere num ângulo de $50-55^{\circ}$ no eixo longitudinal do fêmur, sendo considerado o principal estabilizador dinâmico medial da articulação femoropatelar (11).

Da mesma forma, o músculo VL também é dividido em duas porções: as fibras proximais, que se originam no fêmur e se inserem no terço medial do tendão do músculo quadríceps da coxa, constituindo o músculo vasto lateral longo (VLL), e as fibras póstero-laterais, que se originam no tracto iliotibial, sendo mais oblíquas em sua direção, e se inserem na base e na borda lateral da patela, representando o músculo vasto lateral oblíquo (VLO) (11).

Levando em consideração as origens e as inserções dos músculos VM e VL, especialmente de suas porções oblíquas, pode-se considerar que a tração do VMO e do VLO é importante, já que é o fator muscular que determina a posição da patela. Esses músculos ainda apresentam um comportamento sincrônico com uma função antagonista na estabilização patelar de indivíduos normais $(1,8)$.
A força exercida pelo músculo VLO está relacionada ao tracto iliotibial e ao retináculo lateral, podendo ser capaz de alterar o equilíbrio normal da patela, gerando assim tensão excessiva nessas estruturas e podendo desencadear um quadro de dor e mau alinhamento patelar (1). 0 início retardado e a diminuição na magnitude de ativação do VMO em relação ao VL levam a um movimento lateral anormal e o aumento na pressão de contato femoropatelar é resultante da patologia na cartilagem articular. A redução da capacidade de produção de força dos músculos VMO ou a alteração no controle motor dos músculos VMO e VL são propostas como possíveis causas de desequilíbrio (4).

0 desequilíbrio dos estabilizadores dinâmicos está relacionado com as forças entre os músculos vasto medial oblíquo (VMO) e vasto lateral (VL) (3, 5), principais estabilizadores dinâmicos da patela, sendo esse desequilíbrio considerado o fator primordial para o surgimento dos sintomas, o que, no entanto, altera a cinemática patelar e contribui para o aumento das forças de reação e compressão femoropatelares (3).

O desalinhamento do mecanismo extensor é uma característica muito comum dessa patologia, promovendo atrofia e diminuição da força do músculo vasto medial e desequilíbrio entre os componentes laterais e mediais do quadríceps (1).

A cadeia cinética é um termo utilizado para descrever a ativação sequencial dos segmentos do membro da perna, permitindo gerar força, estabilização da perna e transferência da força para a extremidade distal da cadeia (12).

Um exercício em cadeia cinética aberta pode ser considerado uma atividade em que o componente distal da extremidade não está fixo, mas livre no espaço $(4,13)$, proporcionando um movimento do segmento de forma isolada (6). Além disso, comumente considera-se que nesse tipo de exercício não há descarga de peso (12). A cadeia cinética fechada envolve exercícios com movimentos multiarticulares executados com a extremidade distal fixa $(4,13)$, frequentemente com descarga de peso associada $(4,12)$.

Esses exercícios geram a cocontração dos músculos agonistas e antagonistas, a fim de proporcionar maior estabilização articular $(3,13)$, produzindo ainda menor carga de cisalhamento anterior da tíbia, aumentando a força de compressão tibiofemoral e diminuindo as forças compressivas femoropatelares perto da extensão (14). Para Fagan e Delahunt 
(4), a propriocepção também é um fator influente na escolha desses exercícios, pois se acredita que o feedback seja mais eficiente graças às forças de compressão do corpo e o contato do pé com o chão, além de reproduzir movimentos funcionais comumente executados nas atividades de vida diária $(3,4,7)$.

Os dados existentes na literatura sobre a comparação dessas duas cadeias ainda se apresentam de forma inconclusiva. Além disso, os benefícios para a aplicação desses protocolos não são bem documentados. Dessa forma, o objetivo deste estudo é revisar a literatura para comparar a eficácia dos exercícios em cadeia cinética aberta com os em cadeia cinética fechada, para a recuperação funcional dos portadores da disfunção femoropatelar.

\section{Metodologia}

Para a realização deste estudo, foram pesquisados artigos de revistas que são acessadas por meio das bases de dados LILACS, MEDLINE, SciELO e PubMed, desde o ano de 1998 até 2008. A estratégia de busca correlacionava as seguintes palavras-chave: reabilitação patelofemoral, cadeia cinética aberta, cadeia cinética fechada, disfunção femoropatelar, força patelofemoral, biomecânica patelofemoral. Os idiomas analisados foram o português e o inglês. Como critério de inclusão para a seleção dos trabalhos pesquisados, levou-se em conta a relação com a patologia e os exercícios propostos, além da data de publicação desses estudos.

\section{Discussão}

Durante a realização do exercício em cadeia cinética aberta, o músculo quadríceps femoral atua de forma isolada, aumentando as forças de compressão femoropatelares (3). Nesse tipo de exercício, o centro de gravidade está à frente do joelho, fazendo com que a força seja maior na flexão de $90^{\circ}$ até a extensão $\left(0^{\circ}\right)(10)$. Até os $30^{\circ}$, o ângulo entre as forças é muito pequeno para gerar estresses compressivos altos entre a patela e os côndilos e a área de contato diminui de $90^{\circ}$ a $0^{\circ}$. Com uma força maior e uma área de contato menor, a pressão é máxima, em torno de $35^{\circ}$ a $45^{\circ}$, diminuindo na sequência porque a angulação é muito pequena. Então, o exercício em cadeia cinética aberta pode ser realizado de $0^{\circ}$ até $15^{\circ}$ e de $50^{\circ}$ a $90^{\circ}$ no indivíduo com DFP, não realizando o exercício de $35^{\circ}$ a $45^{\circ}$, em que a pressão de contato é muito alta, já que a magnitude do contato femoropatelar cresce de $0^{\circ}$ a $60^{\circ}$ e não muda muito de $60^{\circ}$ a $90^{\circ}(10)$.

Segundo Fehr et al. (3), devem ser evitados os últimos graus de extensão do joelho, já que nessa angulação há menor contato articular, porém, as forças compressivas são distribuídas sobre uma pequena área, aumentando o estresse femoropatelar. Segundo Grossi et al. (1), os últimos graus de extensão do joelho no exercício em cadeia cinética aberta proporcionam menor contato articular e, portanto, menor instabilidade. Ocorre também maior estresse femoropatelar, já que o contato articular nessa angulação é menor e, portanto, as forças compressivas, apesar de menores, são distribuídas numa menor área de contato, aumentando o estresse.

0 conceito de que o músculo VMO é mais ativo durante os últimos graus de extensão é amplamente aceito por Grossi, Pedro e Berzin (1) e por Escamilla, Fleisig, Zheng, Barrentine, Wilk e Andrews (15). Como esse músculo é difícil de isolar, um exercício - realizado em cadeia cinética aberta - proposto por O'Sullivan e Popelas (2) em seu estudo, mostrou que nos últimos graus de extensão do joelho com rotação medial da tíbia obteve-se melhor ativação do VMO.

No exercício de cadeia cinética fechada, o centro de gravidade é localizado atrás do joelho, assim a força vai aumentando de $0^{\circ}$ até $90^{\circ}$. Esse aumento na força é acompanhado por um aumento da área de contato até os $60^{\circ}$ e, a partir daí, a área de contato não aumenta em proporção com a força, fazendo com que a pressão na patela aumente (10). A flexão de joelho a $90^{\circ}$ apresenta maior força de reação femoropatelar, sendo maior, também, o contato articular e a estabilidade femoropatelar. Sendo assim, o estresse femoropatelar diminui à medida que aumenta o ângulo de flexão do joelho (1).

Segundo Grossi et al. (5), os exercícios em cadeia cinética fechada nos primeiros $60^{\circ}$ de flexão do joelho são mais tolerados pelos indivíduos com DFP. Para Souza et al. (13), na amplitude de $0^{\circ}$ a $50^{\circ}$ de flexão do joelho ocorrem as menores forças de cisalhamento anterior na articulação tibiofemoral. Fehr et al. (3) dizem que devem ser evitados ângulos acima de $45^{\circ}$ de flexão do joelho, pois, apesar de maior estabilidade articular com incremento da flexão, há também aumento das forças compressivas e maior estresse femoropatelar. Peccin e Chamlian (16) apon- 
tam que, de $0^{\circ}$ a $30^{\circ}$ de flexão de quadril, as forças de reação da femoropatelar diminuem, bem como o estresse dessa articulação quando comparado com o exercício em cadeia cinética aberta. As atividades em cadeia cinética fechada, no entanto, devem estar num ângulo entre $0^{\circ} \mathrm{e} 30^{\circ}$, pois de $60^{\circ}$ a $90^{\circ}$ ocorre um aumento de estresse sobre essa articulação. Já Cabral et al. (6) relatam que os exercícios realizados nos primeiros graus de flexão também causam menor tração patelar lateral.

Nesse tipo de exercício observa-se maior amplitude do sinal do VMO quando comparado com os exercícios de cadeia cinética aberta. Contudo, o sinal do VMO é menor que o do VL, tanto em cadeia cinética fechada como aberta (6). Para o fortalecimento seletivo do músculo VMO, o que se procura não é somente o arco de movimento em que apresente maior atividade, mas que também possa oferecer maior estabilidade, maior distribuição de forças compressivas e maior ativação em relação aos componentes laterais. Na angulação de $90^{\circ}$, as forças compressivas são maximizadas e a força de cisalhamento é minimizada, facilitando não somente a atividade do músculo VMO, mas aumentando o contato articular e favorecendo a nutrição articular (1).

No exercício em cadeia cinética fechada ocorre a cocontração dos isquiotibiais. Em pequenos ângulos de flexão, essa cocontração diminui a translação anterior da tíbia e a rotação interna causada pelo quadríceps, contudo, em ângulos acima de $60^{\circ}$ essa cocontração faz com que a tíbia se desloque posteriormente e rode externamente. Esse deslocamento posterior e a rotação externa aumentam a pressão na patela, assim como a força de contato é maior acima de $50^{\circ}$ e a cocontração dos isquiotibiais aumenta a pressão a partir de $60^{\circ}(10)$.

Dentre os exercícios em CCF, o de agachamento é considerado seguro e efetivo graças ao efeito estabilizador da cocontração dos músculos quadríceps e isquiotibiais (5). Esse exercício deve ser realizado até próximo dos $50^{\circ}$, para não gerar tanta força e pressão na articulação patelofemoral (10).

Durante o agachamento, a linha de gravidade se desloca posteriormente ao eixo do joelho, aumentando o torque flexor. Os isquiotibiais promovem estabilização no joelho mediante tração posterior na tíbia para contrapor a força anterior imposta pelo quadríceps. 0 grau de ativação em que os músculos isquiotibiais atuam na pelve depende dos ângulos do joelho do quadril e dos comprimentos muscula- res individuais. Dessa forma, a tensão dos isquiotibiais pode ser aumentada com uma ligeira flexão anterior do tronco, o que também move o centro de gravidade anteriormente, diminuindo o torque de flexão do joelho e reduzindo, assim, a força de translação tibial e a compressão na articulação patelofemoral (13).

Grossi et al. (5) observaram que com o aumento da flexão do joelho usando a técnica do agachamento se proporciona maior ativação elétrica dos músculo VMO e VL. Isso ocorre em razão do reto femoral ser mais ativo nessa cadeia e, consequentemente, o VMO aumenta sua atividade elétrica para manter a patela no seu alinhamento adequado. De forma geral, o músculo quadríceps apresenta maior atividade elétrica na medida em que aumenta o ângulo de flexão do joelho. Num estudo proposto por O'Sullivan e Popelas (2), observou-se que o agachamento com rotação externa de quadril e flexão de joelho a $60^{\circ}$ produz maior grau de ativação do músculo VMO.

Zwerver et al. (17) relataram em seu estudo que o agachamento unipodal realizado em uma plataforma de declínio de forma excêntrica mostrou ser de melhor eficácia para o fortalecimento da região extensora do joelho quando comparado com o agachamento normal e em piso plano. Os autores acreditam que é pelo fato de que nas posições em pé e em declínio ocorra a redução do momento da força do quadril e do tornozelo durante o exercício. Dessa forma, os extensores do joelho e o tendão patelar são carregados ao máximo quando realizados em uma placa de $15-30^{\circ}$. Quanto à flexão de joelho, devem ser evitados os $60^{\circ}$, pois nessa angulação o contato femoropatelar já é cerca de nove vezes a força do corpo. Sendo assim, para evitar disfunção femoropatelar, recomenda-se evitar a flexão do joelho durante o exercício de agachamento acima dos $60^{\circ}$.

A ativação do músculo reto femoral mostrou-se maximizada com a elevação do ângulo de flexão do joelho a $90^{\circ}$. Observando os exercícios em cadeia cinética fechada, a maior atividade do reto femoral é produzida entre $83^{\circ}$ e $95^{\circ}$ de flexão do joelho. Essa angulação aumenta as forças compressivas nas articulações tibiofemoral e patelofemoral (14).

\section{Conclusão}

Após este levantamento podemos concluir que, dentre os protocolos de tratamento, os exercícios em 
cadeia cinética aberta e fechada mostraram que podem reduzir a dor e aumentar a força muscular dos portadores de disfunção femoropatelar. A abordagem terapêutica combinada com essas duas cadeias é recomendada, porém, os exercícios em cadeia cinética fechada têm sido considerados mais funcionais para a reabilitação de indivíduos com DFP. No entanto, faltam evidências científicas que comprovem a real eficácia desses exercícios em melhorar o desempenho do músculo quadríceps da coxa ou auxiliar no equilíbrio muscular dos estabilizadores dinâmicos da patela. Sendo assim, tornam-se necessários mais estudos biomecânicos, eletromiográficos e anatômicos que permitam uma comparação entre eles, a fim de embasar a aplicação de exercícios no tratamento de pacientes com essa patologia.

\section{Referências}

1. Grossi DB, Pedro VM, Berzin F. Análise funcional dos estabilizadores patelares. Acta Ortop Bras. 2004; 12(2):99-104.

2. O'Sullivan SP, Popelas CA. Activation of vastus medialis obliquus among individuals with patellofemoral pain syndrome. J Strength Cond Res. 2005;19(2):302-4.

3. Fehr GL, Cliquet Jr A, Cacho EWA, Miranda JB. Efetividade dos exercícios em cadeia cinética aberta e cadeia cinética fechada no tratamento da síndrome da dor femoropatelar. Rev Bras Med Esporte. 2006;12(2):66-70.

4. Fagan V, Delahunt E. Patellofemoral pain syndrome: a review on the associated neuromuscular deficits and current treatment options. Br J Sports Med. 2008; 42(10):789-95.

5. Grossi DB, Felicio LR, Simões R, Coqueiro KRR, Pedro VM. Avaliação eletromiográfica dos músculos estabilizadores da patela durante exercício isométrico de agachamento em indivíduos com síndrome da dor femoropatelar. Rev Bras Med Esporte. 2005;11(3):159-63.

6. Cabral CMN, Melim AMO, Sacco ICN, Marques AP. Fisioterapia em pacientes com síndrome fêmoro-patelar: comparação de exercícios em cadeia cinética aberta e fechada. Acta Ortop Bras. 2008;16(3):180-5.

7. Witvrouw E, Danneels L, Tiggelen DV, Willems TM, Cambier D. Open versus closed kinetic chain exercises in patellofemoral pain. A 5-year prospective randomized study. Am J Sports Med. 2004;32(5):1122-30.
8. Cohen M, Abdalla RJ, Ferretti Filho M, Silva PRG. Síndrome femoropatelar. In: Cohen M, Abdalla RJ. Lesões no esporte: diagnóstico, prevenção e tratamento. Rio de Janeiro: Revinter; 2002.

9. Turek SL. Ortopedia: princípios e sua aplicação. São Paulo: Manole; 1991.

10. Haupentbal A, dos Santos DP. Força e contato patelofemoral como fundamentos biomecânicos para reabilitação da síndrome patelofemoral. Fisioter Mov. 2006;19(4):11-6.

11. Cabral CMN, Monteiro PV. Recuperação funcional de indivíduos com disfunção fêmoro-patelar por meio de exercícios em cadeia cinética fechada: revisão de literatura. Rev Bras Fisioter. 2003;7(1):1-8.

12. Davies GJ, Heiderscheit BC, Clark M. Reabilitação em cadeia cinética aberta e fechada. In: Ellenbecker TS. Reabilitação dos ligamentos do joelho. São Paulo: Manole; 2006. p. 160-88.

13. de Sousa CO, Ferreira JJA, Medeiros ACLV, Pereira RC, Guedes DT, de Alencar JF. Atividade eletromiográfica no agachamento nas posições de $40^{\circ}, 60^{\circ}$ e $90^{\circ}$ de flexão do joelho. Rev Bras Med Esporte. 2007;13(5):310-6.

14. Fleming BC, Oksendahl H, Beynnon BD. Open-or closed-kinetic chain exercises after anterior cruciate ligament reconstruction?. Exerc Sport Sci Rev. 2005; 33(3):134-40.

15. Escamilla RF, Fleisig GS, Zheng N, Barrentine SW, Wilk $\mathrm{KE}$, Andrews JR. Biomechanics of the knee during closed kinetic chain and open kinetic chain exercises. Med Sci Sports Exerc. 1998;30(4):556-69.

16. Peccin MS, Chamlian TR. Princípio da reabilitação femoropatelar. In: Cohen M, Abdalla R. Lesões nos esportes: diagnóstico, prevenção e tratamento. Rio de Janeiro: Revinter; 2002. p. 535-43.

17. Zwerver J, Bredeweg SW, Hof AL. Biomechanical analysis of the single-leg decline squat. Br J Sports Med. 2007;41(4):264-8

Recebido: 29/06/2010 Received: 06/29/2010

Aprovado: 24/09/2010 Approved: 09/24/2010 